\title{
Protein crystallization with and without precipitants
}

\author{
Joachim Behlke,* Andreas Marg and Manfred Paeschie at Max Delbrück Center for Molecular Medicine, \\ Robert Rössle Strasse 10,D13122 Berlin, Germany.E-mail: behlke@mdc-berlin.de
}

(Received 3 February 1997; accepted 7 February 1997)

\begin{abstract}
Crystals for X-ray structure analysis can be obtained from supersaturated protein solutions using the vapour-diffusion technique. Added electrolytes can act as competitors for water in the droplets as well as to reduce the activity of water and decrease the water vaporization rate. The water vaporization rate is critical for the protein crystallization process. It is a function of the type of electrolyte used and can be altered when testing the influence of various electrolytes on protein crystallization. Here we present a new approach to controlling the water vaporization rate using a vacuum pump to lower the pressure during the crystallization process. The successful application of the method for crystallization of adrenodoxin is described.
\end{abstract}

\section{Introduction}

At present, far more than 100 different proteins have been crystallized for X-ray structure analysis. To obtain crystals of proper quality, individual treatment of proteins in supersaturated solutions is often necessary. The most widely used method for obtaining supersaturation in microdrops of protein in mother liquid is vapour diffusion (McPherson, 1990). This technique is available in different variants of 'hanging drop' or 'sitting drop'. Using these methods, a slow transport of water molecules from the microdrop of mother liquid to the larger reservoir solution containing precipitants is achieved (Fowlis et al., 1988). During this procedure, salts exert their effect by

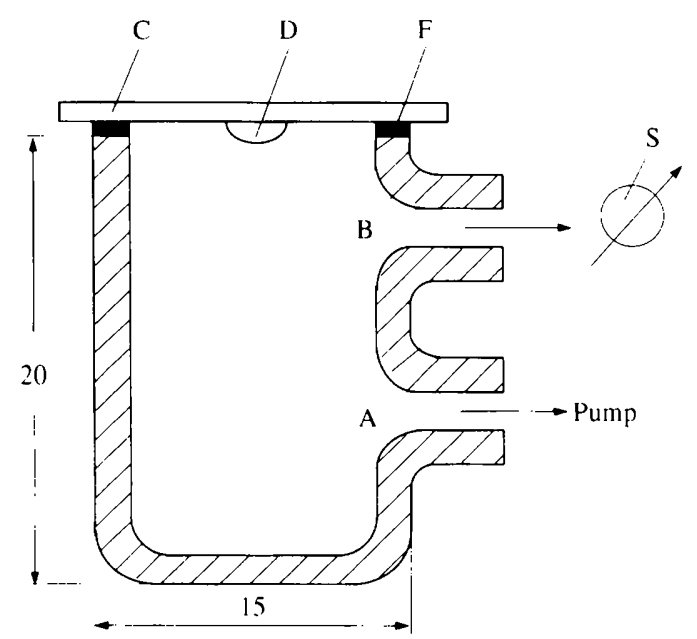

Fig. 1. Side view of the crystallization vessel (size given in $\mathrm{mm}$ ) with two additional links, $A$ to a vacuum pump and $B$ to a pressure sensor (S). The cover slip (C) with the droplet (D) of protein and grease (F) seals the vessel as usual. dehydration of proteins through competition for water molecules. Because the dehydrating effect of ions is proportional to the square of ion charge, multivalent ions, especially the lyotropic ions such as sulfates, phosphates or citrates, have been employed successfully (McPherson, 1990). Besides dehydration and lowering the chemical activity of water, some of the added salts can also induce specific interactions with the protein. On the other hand, changes of salt as precipitant can sometimes lead to crystals with different space groups (Riès-Kautt \& Ducruix, 1989). Since crystal growth is influenced by the rate of removal of water molecules from the droplet, one has to be careful to use the appropriate molarity of substituted salts. Because the vapour-pressure equilibrium in the closed system between droplet and reservoir depends strongly on the colligative properties of precipitants, we have analyzed the crystallization of adrenodoxin by different salts in varying concentrations at the same rate of vapour-pressure decrease. In addition, we have replaced the electrolyte effect by a controlled pressure decrease using a vacuum pump.

\section{Procedures}

\subsection{Crystallization experiments with precipitants}

The electron-transfer protein, adrenodoxin, isolated and purified as described by Marg (1994), was crystallized by the 'hanging-drop' method. Droplets of $10 \mu \mathrm{l}$ protein $\left(10 \mathrm{mg} \mathrm{ml}^{-1}\right.$ in $100 \mathrm{~m} M$ potassium phosphate, $\mathrm{pH} \mathrm{8.2)} \mathrm{were} \mathrm{put} \mathrm{on} \mathrm{a} \mathrm{cover}$ slip over $500 \mu \mathrm{l}$ reservoir solution containing $55 \mathrm{mM}$ Tris $-\mathrm{HCl}$, $\mathrm{pH} 7.5$ and various concentrations of $\left(\mathrm{NH}_{4}\right)_{2} \mathrm{SO}_{4}, \mathrm{KCl}, \mathrm{NaCl}$ or $\mathrm{CaCl}_{2}$ at $277 \mathrm{~K}$. Typical brown-coloured hexagonal crystals, as described previously (Marg, Kuban, Behlke, Dettmer \& Ruckpaul, 1992), were obtained after 2-3 d when using the salt concentrations indicated in Table 1 . All chosen concentrations of the different electrolytes correspond to identical colligative properties with regard to the vapour-pressure decrease of about $25 \mathrm{~mm}$ (Landolt \& Börnstein, 1931). When using considerably higher or lower salt concentrations in the reservoir, the crystallization experiments were unsuccessful, indicating the importance of colligative properties in crystallization experiments.

\subsection{Crystallization experiments without precipitants}

If vapour-pressure reduction is the major driving force for protein crystallization, the process should be possible even without precipitants. To confirm this hypothesis, we have constructed a special vessel (Fig. 1) which is connected by a pressure sensor and a vacuum pump that permits a controlled pressure decrease below the hanging drop. In the crystallization experiment, the vaporizing water from the droplet at first is continuously removed and in about $1 \mathrm{~h}$ the vapour pressure is lowered by the pump to $25 \mathrm{~mm}$ and kept constant against the outer pressure for the next $2 \mathrm{~d}$. During this time, the protein 
Table 1. Concentrations of different salts in the reservoir which are able to induce the crystallization of adrenodoxin

\begin{tabular}{lll} 
& \multicolumn{2}{c}{ Concentration } \\
Salt & $\left(\mathrm{g} 100 \mathrm{ml}^{-1}\right)$ & $(M)$ \\
$\left(\mathrm{NH}_{4}\right)_{2} \mathrm{SO}_{4}$ & 34.0 & 2.50 \\
$\mathrm{KCl}$ & 19.0 & 2.52 \\
$\mathrm{CaCl}$ & 15.0 & 1.36 \\
$\mathrm{NaCl}$ & 14.0 & 2.39
\end{tabular}

concentration in the droplet has increased in such a manner that crystals appear. For further crystal growth, which can be seen using a microscope, the pressure difference of $25 \mathrm{~mm}$ is decreased to about $5 \mathrm{~mm}$ during the next $24 \mathrm{~h}$. In this time, brown hexagonal crystals of adrenodoxin of nearly $0.3 \mathrm{~mm}$ length were obtained, comparable with those obtained by conventional methods (Marg et al., 1992). The advantage of the presented procedure can be seen in the possibility of regulating the vapour-pressure equilibrium, which is necessary for nucleation and crystal growth.

\section{References}

Fowlis, W. W., DeLucas, L. J., Twigg, P. J., Howard, S. B., Meehan, E. J. Jr \& Baird, J. K. (1988). J. Cryst. Growth, 90, 117-129.

Landolt, H. \& Börnstein, R. (1931). Physikalische Chemische Tabellen, edited by W. A. Roth \& K. Scheel, pp. 1318-1327. Berlin: Springer. McPherson, A. (1990). Eur. J. Biochem. 189, 1-23.

Marg, A. (1994). PhD thesis, Humboldt-University, Berlin, Germany. Marg, A., Kuban, R.-J., Behlke, J., Dettmer, R. \& Ruckpaul, K. (1992). J. Mol. Biol. 227, 945-947.

Riès-Kautt, M. M. \& Ducruix, A. F. (1989). J. Biol. Chem. 264,745748. 